\title{
Caro's Acid-Silica Gel Catalyzed Regioselective Ring Opening of Epoxides with Indoles and Imidazoles under Solvent-Free Conditions
}

\author{
Majid Momahed Heravi (Đ), Hoda Hamidi @**, Narges Karimi, Akram Amouchi \\ Department of Physics and Chemistry, Alzahra University, Tehran,P.O. Box 1993891176, Iran \\ *Corresponding author E-mail: hamidi hoda@yahoo.com, Tel.: +982188044051; Fax: +982188041344
}

Received: 23 September 2018, Revised: 15 October 2018, Accepted: 6 November 2018

\begin{abstract}
A B ST R A C T
An efficient and facile procedure has been developed for the ring opening of epoxides with nitrogen heterocycles such as indole and imidazole in the presence of Caro's acid-silica gel $\left(\mathrm{CA}-\mathrm{SiO}_{2}\right)$ as catalyst in solventless system. The reactions were administered underneath Solvent-free conditions. The current methodology offers many benefits like good yields, easy procedure, simple work-up and ecofriendly reaction condition. The catalyst is well ready, stable and economical underneath the reaction conditions.
\end{abstract}

Keywords: Regioselectivity, Indole, Imidazole, Epoxide, Caro's acid-silica gel.

\section{GRAPHICALABSTRACT}

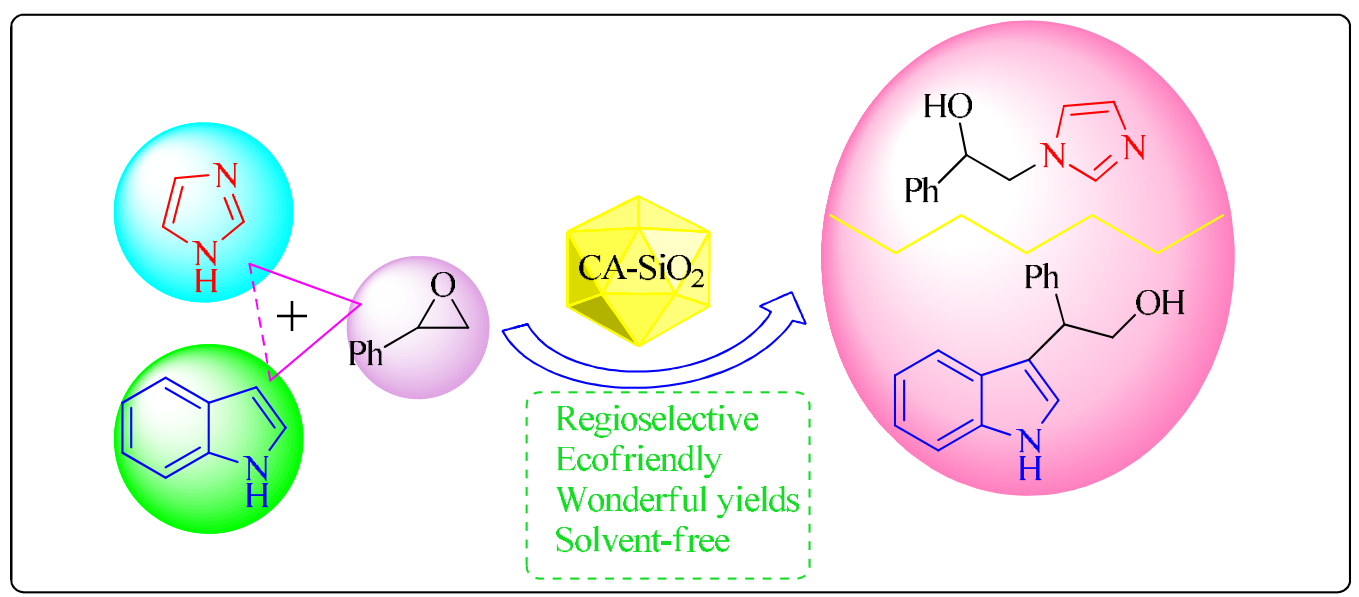

\section{Introduction}

The indole nucleus is usually found in some medicines, especially those have an origin of natural products and agrochemicals [1]. Substituted indoles are capable of binding to many receptors with high affinity. Therefore, the synthesis and selective functionalization of the synthesis and selective functionalization of indoles have been always attracted the attention of synthetic organic chemists, over the years [2-4].
3-Substituted indoles are essential building blocks for the synthesis of various active molecules. Consequently, its synthesis has stirred up the interest of synthetic organic chemists for development of and introduction of new methodologies towards 3-substituted indoles [5]. Among heterocycles, the presence of 1,3-azole moieties seems vital in order to give biological activity and potency to some certain drugs [6]. The synthesis of this family of heterocyclic 
compounds mainly achieved either via ring closure reactions of appropriate acyclic precursors orby substituent modification of heterocyclic systems. These compounds are worthwhile being evaluated and screened under medicative analysis systems [7]. Epoxides are recognized an important and versatile synthetic intermediates in organic synthesis [8] due to their exceptional reactivity, especially being receptive to nucleophilic attack .They are also commercially available and readily accessible in pure form [9]. Therefore, there is continuous and current interest in the ring opening of epoxides with several kinds of different reagents such as electrophiles, nucleophiles, acids, base, reducing agents, and a few oxidizing agents. Several procedures for the catalyzed ringopining reaction of epoxides with indole have been reported in the literature using Lewis acid such as $\mathrm{SiO}_{2}$ [10], $\mathrm{InCl}_{3}$ [11] and $\mathrm{InBr}_{3}$ [12] or being performed under high pressure. One special but rare case of 3-azoles are the 1-(2hydroxyalkyl)imidazole derivatives. Several of them are showing antifungal properties [13]. These compounds have been synthesized via epoxides ring opening upon reaction with imidazole derivatives . To perform this reaction, obtaing good yields a harsh conditions (such as strong base/high temperature [14] or high pressure [10]) are required. Since these compounds are interesting from both chemical and biological points of view , developments and modifications are still in much demands. Recently, the applications of Caro's acid-silica gel $\left(\mathrm{CA}-\mathrm{SiO}_{2}\right)$ as catalysts or promoters in organic synthesis has attracted much interest of synthetic organic chemists. $\mathrm{CA}-\mathrm{SiO}_{2}$ catalyzed reaction, enhancing the reactivity and selectivity for several kind of reactions, such as oxidative coupling of thiols to disulfides [15], conversion of thioamides into amides [16], carbonyl compounds from oximes [17], synthesis xanthen [18] and synthesis tetrahydrobenzo[b]pyran [19], have been reported [20]. We are interested in heterocyclic chemistry [21-26]. We have also reported in ring opening of epoxides using different catalysts [27]. We have recently used Caro's acid-silicagel as a catalyst [28,29]. Herein we wish to disclose our result Caro's acid-silica gel catalyzed regioselective ring opening of epoxides with indoles and imidazoles under solvent-free conditions on.

\section{Experimental}

Melting points were measured by using the capillary tube technique with an electro thermal 9200 apparatus. GC-Mass analysis was performed on a GC-Mass model: 5973 network mass selective detector, GC 6890 egilent Mass spectra were obtained with a Massens POEKTROMETER CH-7A VARIN MAT BREMEN spectrometer. IR spectra were recorded from KBr disk on the FT-IR Bruker Tensor 27. ${ }^{1} \mathrm{H}$ NMR spectra were recorded on a Bruker AQS Avance 500-MHz spectrometer using tetramethylsilane (TMS) as an internal standard.

\subsection{General Procedure}

A combination of indole $(\mathbf{1})$ (1 $\mathrm{mmol})$ or imidazole(4) (1 mmol) and styrene oxide(2) (1 $\mathrm{mmol}$ ) and $\mathrm{CA}_{-} \mathrm{SiO}_{2}(0.13 \mathrm{mmom}, 0.078 \mathrm{gr}$ ) was speedily stirred at room temperature for the required time (Table 2,3). After the TLC indicates the disappearance of beginning materials, EtOH $(20 \mathrm{~mL})$ was value-added and also the insoluble material was filtered to separate the catalyst 


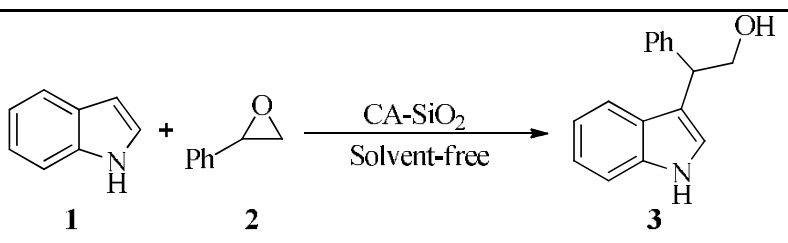

Scheme 1. Alkylation of indoles using $\mathrm{CA}-\mathrm{SiO}_{2}$ under solvent-free

Table 1. Alkylation of indoles using $\mathrm{CA}-\mathrm{SiO}_{2}$ under Solvent-free

\begin{tabular}{|c|c|c|c|c|c|c|}
\hline Entry & Nucleophile & Epoxide & Product & $\operatorname{Mp}\left({ }^{\circ} \mathrm{C}\right)$ & $\begin{array}{l}\text { Time } \\
(\min )\end{array}$ & Yield (\%) \\
\hline 1 & & & & $84-85^{10}$ & 20 & 90 \\
\hline 2 & & & & $85-86^{10}$ & 40 & 88 \\
\hline 3 & & & & $140-142^{10}$ & 60 & 80 \\
\hline 4 & & & & $129-131^{10}$ & 60 & 85 \\
\hline 5 & & & & $92-95^{10}$ & 64 & 83 \\
\hline
\end{tabular}

then EtOH evaporated to afford the pure product $\mathbf{3 a}$ and $\mathbf{5 a}$.

\subsection{Preparation of Catalyst}

In small portions of potassium persulfate (4.5 g) were added to ice-cooled 98\% sulfuric acid (4.7 g) with stirring; to this, crushed ice (13 g) and water $(4 \mathrm{~g})$ were added. The temperature was kept below $15{ }^{\circ} \mathrm{C}$. Silica gel (5 g, TLC grade, Kieselgel $60 \mathrm{G}$, particle size $15 \mathrm{~mm}$ ) was added in portions to the mixture, and the mixture was stirred for $4 \mathrm{~h}$ in an ice-water bath. The mixture was then filtered under suction and dried in a desiccator to give a white free-flowing power [15].

2-(1H-indol-3-yl)-2-phenylethanol (3a) [10]: M.p. 121-122 으, IR (KBr): 3412, 3321, 3056, 3027, 2926, 2874, 1601, 1491, 1453, 1306, 1223, 1054, 744, $700 \mathrm{~cm}-1,1 \mathrm{H}$ NMR $(500 \mathrm{MHz}$, CDCl3): 1.64 (br,1H, OH); 4.39-4.42 (dd, 2H, J= 8 and $6.5 \mathrm{~Hz}, \mathrm{CH} 2) ; 4.53-4.56(\mathrm{t}, 1 \mathrm{H}, \mathrm{J}=7.5 \mathrm{~Hz}$, 
$\mathrm{CH})$, 7.09-7.12 (t, 1H, J = $7 \mathrm{~Hz}, \mathrm{ArH}) ; 7.15(\mathrm{~s}, 1 \mathrm{H}$, ArH); 7.17-7.20 (t, 1H, J = 7 Hz, ArH); 7.24-7.35 (m, 4H, ArH); 7.41-7.43 (d, 2H, J =7 Hz, ArH); 7.53-7.55 (d, 1H, J = 7.5 Hz, ArH); $8.1(\mathrm{br}, 1 \mathrm{H}$, NH) ppm, MS: m/z $237[\mathrm{M}+], 219,206,191$, $178,165,151,128,115,102,77$.

2-(1H-imidazol-1-yl)-1-phenylethanol (5a) [10]: M.p. 145-148 으, IR (KBr): 3689, 2955 cm-1, 1H NMR (500 MHz, CDCL3) 3.45 (s, 1H, OH); 4.10 (m, 2H, CH2); 4.86 (m, 1H, CHOH); 6.87-6.90 2 (s, $1 \mathrm{H}$ and $1 \mathrm{H}, \mathrm{NCHCHN}) ; 7.25-7.36$ (m, 6H, ArH and NCHN) ppm, MS: m/z 189 [M++1], 188, 107, 82.

\section{Results and Discussion}

In order to work out the foremost acceptable reaction conditions and a evaluate the action efficiency of $\mathrm{CA}-\mathrm{SiO}_{2}$ catalyst, at the beginning a model study was administrated on the synthesis of 3a (Scheme 1).

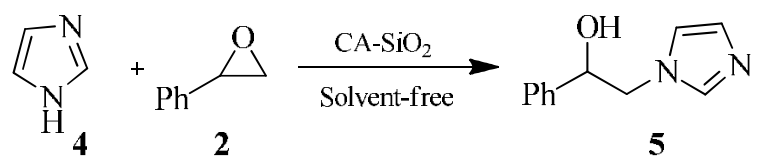

Scheme 2. Alkylation of epoxides using $\mathrm{CA}-\mathrm{SiO}_{2}$ under solvent- free

Table 2. Alkylation of epoxides using $\mathrm{CA}-\mathrm{SiO}_{2}$ under Solvent- free conditions

\begin{tabular}{|c|c|c|c|c|c|c|}
\hline Entry & Nucleophile & Epoxide & Product & $\mathrm{Mp}\left({ }^{\circ} \mathrm{C}\right)$ & $\begin{array}{l}\text { Time } \\
(\mathrm{min})\end{array}$ & Yield (\%) \\
\hline 1 & & & & $84-85^{10}$ & 25 & 80 \\
\hline 2 & & & & $143-144^{10}$ & 65 & 87 \\
\hline 3 & & & & $116-117^{10}$ & 40 & 84 \\
\hline 4 & & & & $117-119^{10}$ & 35 & 86 \\
\hline
\end{tabular}

Encouraged by these results, we have a tendency to applied reaction of imidazole with epoxide within the presence of $0.13 \mathrm{mmol} C A-$ $\mathrm{SiO}_{2}$ at underneath solvent-free conditions, that afforded imidazolyl alcohols in good yields among a brief amount of time (Scheme 2, Table 2). Imidazole, with a pka of 7.1 could be a abundantly stronger base and nucleophile than indole, consequently imidazoles is alkylated on nitrogen simply. Ring opening occurred completely at less hindered carbon of the epoxide. This can be according to $\mathrm{S}_{\mathrm{N}} 2$-type attack by the imidazole nitrogen. All product (Table 1,2) obtained were totally characterised 
by spectroscopical strategies as well as $1 \mathrm{HNMR}$, IR and spectrometry and conjointly by the comparison of the spectral information with according values.

\section{Conclusion}

We represented herein $\mathrm{CA}-\mathrm{SiO}_{2}$ catalyzed extremely economical, protocol for preparation of reaction epoxides with nitrogen heterocycles underneath Solvent-free in good yields. simple work-up, cheap, prepared convenience of the catalyst makes the procedure a horny different to the prevailing strategies for preparation of reaction epoxides with nitrogen heterocycles. Acknowledgment The authors are grateful for the partial financial support from Alzahra University research council via special grant.

\section{ORCID}

Hoda Hamidi (10: 0000-0002-5019-8591

\section{References}

[1]. L. Ninomiya, J. Nat. Prod., 1992, 55, 541-564. [2]. J.F. Austin, D.W.C. MacMillan, J. Am. Chem. Soc., 2002, 124, 1172-1173.

[3]. N. Srivastava, B.K. Banik J. Org. Chem., 2003, 68, 2109-2114.

[4]. N. Yoshiaki, Y. Masato, I. Youichi, H. Masnobu, U. Sakae, J. Am. Chem. Soc., 2002, 124, 11846-11847.

[5]. K.R. Campos, J.C.S. Woo, S. Lee, R.D. Tillyer Org. Lett., 2004, 6, 79-82.

[6]. A.R. Katritzky, C.W. Rees, E.F. Scriven M.R. Grimmet,Comprehensive Hetrocyclic Chemistry II, Pergamon Oxford, 1996, P 342.

[7]. C.A. Zificsak, D.J. Hlasta Tetrahedron, 2004, 60, 8991-9016.

[8]. R.E. Parker, N.S. Isaacs, Chem. Rev., 1959, 59, 737-799.

[9]. A. Pfenninger, Synthesis, 1986, 89-116.
[10]. H. Kotsuki, K. Hayashida, T. Shimanouchi, H. Nishizawa, J. Org. Chem., 1996, 61, 984-990.

[11]. J.S. Yadav, B.V.S. Reddy, S. Abraham, G. Sabitha, Synlett, 2002, 1550-1552.

[12]. M. Bandini, P.G. Cozzi, P. Melchiorre, A. Umani-Ronchi J. Org. Chem., 2002, 67, 53865389.

[13]. R. Frimguelli, F. Schiaffella, F. Bistoni, L. Pitzurra, A. Vecchiarelli, Bioorg. Med. Chem., 1998, 6, 103-108.

[14]. G. Cooper, W.J. Irwin, J. Chem. Soc. Perkin Trans 1, 1976, 545-549.

[15]. B. Movassagh, M. Lakouraj, K. Ghodrati Synth. Commun., 1999, 29, 3597-3603.

[16]. B. Movassagh, M. Lakouraj, K. Ghodrati Synth. Commun., 2000, 30, 2353-2358.

[17]. B. Movassagh, M. Lakouraj, K. Ghodrati Synth. Commun., 2000, 30, 4501-4506.

[18]. H.A. Oskooie, M.M. Heravi, N. Karimi, L. Tahershamsi, Synth. Commun., 2011, 41, 307312 .

[19]. H.A. Oskooie, M.M. Heravi, N. Karimi, M. Ebrahim Zadeh, Synth. Commun., 2011, 41, 436440.

[20]. A. Lange, M. Hild, H.D. Brauer, J. Chem. Soc. Perkin Trans 2. 1999, 1343-1350.

[21]. M.M. Heravi, S. Sadjadi, H.A. Oskooie, R.H. Shoar, F.F. Bamoharram, Catal. Commun. 2008, $9,470-474$.

[22]. M.M. Heravi, M. Tajbakhsh, A.N. Ahmadi, B. Mohajerani, Monatsh. chem. 2006, 137, 175-179.

[23]. M.M. Heravi, M. Khorasani, F. Derikvand, H.A. Oskooie, F.F. Bamoharrarn, Catal. Commun. 2007, 8, 1886-1890.

[24]. M.M. Heravi, S. Khaghaninejad, M. Mostofi, Adv. Heterocycl. Chem. 2014, 112, 1-50.

[25]. M.M Heravi., S. Khaghaninejad, N. Nazari, Adv. Heterocycl. Chem. 2014, 112, 183-234

[26]. S. Khaghaninejad, M.M. Heravi, Adv. Heterocycl. Chem., 2014, 111, 95-146. 
[27]. M.M. Heravi, B. Baghernejad, H.A. Oskooie, Catal. Lett. 2009, 130, 547-550.
[29]. N. Karimi, H.A. Oskooie, M.M. Heravi, L. Tahershamsi, Synth. Commun. 2011, 307-312.

[28]. M.M. Heravi, N. Karimi, M.E. Zadeh, Synth. Commun. 2011, 41, 436

How to cite this manuscript: M.M. Heravi, H. Hamidi, N. Karimi, A. Amouchi, Caro's Acid-Silica Gel Catalyzed Regioselective Ring Opening of Epoxides with Indoles and Imidazoles under Solvent-Free Conditions, Adv. J. Chem. A, 2018, 1, 1-6. 